\title{
Quatrocentas Reuniões de Estudos em Mesa Semanal de Debates
}

\author{
Ruy Barbosa Nogueira \\ Professor Presidente do IBDT \\ e Catedrático de Direito Tribu- \\ tário da Faculdade de Direito \\ da Universidade de São Paulo
}

A reunião semanal de Professores de várias Universidades, Magistrados, Procuradores, Advogados, Economistas, Administradores, Contabilistas, altos funcionários da Fazenda Federal, Estadual e Municipal com os bacharéis que estão cursando as áreas de Mestrado $e$ Doutorado em Direito Tributário Comparado na Faculdade de Direito da USP teve como primeiro "desideratum" da Cátedra trazer para estes candidatos de pós-graduação, dentro da própria Faculdade, o manancial de conhecimentos teóricos e práticos dos diferentes setores do vasto campo em que se desdobram as funções e profissões dentro da fenomenologia e da problemática tributária.

Assim, estes candidatos passariam, como passaram a ter, além do ensino e orientação de seus professores, mais o laboratório de experiências, o banco de informações e os conhecimentos dos colaboradores, pois estes trazem numerosos casos e problemas concretos para os debates, estudos e conclusões.

À medida que estes estudos teórico-práticos foram-se evoluindo, fomos observando não só que hoje tais reuniões constantes alcançaram a natureza de um curso e simpósio-permanente para todos que o vem freqüentando, mas ainda que seu caráter facultativo, não curricular ou compulsório vem contribuindo para aquilo que nosso Professor Enrico Tullio Liebman tanto valoriza e aconselha aos estudiosos, como caminho para a formação de Escola. Este Mestre que retornou a Milão, aqui deixou a conhecida Escola Paulista de Processo.

Neste sentido de estudos dialogados também devemos lembrar do genial comercialista Tullio Ascarelli, que igualmente lecionou nesta Faculdade e tanto se dedicou aos estudos jurídicos e às suas relações com a economia. Além de seu aluno no curso de bacharelado e de curso especial, tivemos a ventura de ser seu companheiro de escritório. Mais tarde escrevemos sobre a influência deste Mestre no campo da Ciência do Direito Tributário Brasileiro ${ }^{1}$.

1. Vide TULLIO ASCARELLI E O DIREITO TRIBUTARIO BRASILEIRO, co-edição IBDT e Editora Resenha Tributária, S. Paulo, 1979. Na Itália, publicado na revista Diritto 
Ainda nesta Faculdade, no campo do Direito do Trabalho o Prof. Cesarino Júnior já acrescentava ao seu método de ensino os trabalhos dialogados em seminários e julgamentos simulados e foi fundador do Instituto de Direito Social, como idealizador da Academia Paulista de Direito.

No último ano do curso curricular, a coroar os estudos jurídicos, o Jusfilósofo Miguel Reale, dedicando-se ao mesmo tempo a seus alunos e a seus companheiros de estudos, fundou o Instituto Brasileiro de Filosofia, até hoje em plena atividade, o qual já alcançou notável relacionamento com o exterior.

As obras deste Jusfilósofo, cada vez mais vertidas para outros idiomas e por edições renovadas, vêm sendo adotadas em Universidades estrangeiras, expandindo a cultura pátria e gratificando a Universidade de São Paulo, da qual, por dois mandatos completos, foi notável Reitor. Sem dúvida o foi, não só em razão de sua constante dedicação à Universidade, mas sobretudo em função desse sentido de exteriorização dentro do qual ele compreende a Universidade, a explica e nela se integra como exemplo de Professores que continua a sê-lo, ainda quando a idade o aposenta, porque seus alunos continuam nas Escolas do Direito e da Filosofia que foi capaz de edificar e de dignificar.

Mestre Reale não só formou Escolas, mas dentro delas conseguiu chegar à sua concepção própria da Teoria Geral da Tridimensionalidade do Direito.

Em Dianóia (México, 1967, n 13, pág. 371), Recaséns Siches, com sua competência e autoridade, apreciando as obras do grande Professor brasileiro, atesta que:

"Miguel Reale é, sem dúvida, um dos Jusfilósofos mais eminentes, não só na área ibero-americana, mas no mundo inteiro, em nossa época, por sua universalmente famosa FILOSOFIA DO DIREITO, já traduzida para o italiano.

Uma concepção tridimensional do Direito já se encontra em obras de outros autores, publicadas anteriormente aos primeiros escritos de Reale sobre esse tema, e também em livros coletâneos às publicações de Reale, assim como em outras posteriores a elas. Mas, na minha opinião, a concepção tridimensional do Direito obteve, nas páginas de Miguel Reale, uma expressão ao mesmo tempo mais fina, mais profunda e mais exaustiva.

Quanto a mim, incorporei ao meu próprio pensamento filosófico-jurídico, quase integralmente, a versão que Reale dá à sua doutrina tridimensional"

e Pratica Tributaria, Vol. III, 1981, ne 3, sob o título: "IL CONTRIBUTO DI TULLIO ASCARELLI ALLA FORMAZIONE DELLA DOTTRINA GIURIDICO-TRIBUTARIA DEL $B R A S I L E^{\prime \prime}$, págs. $553 / 568$ e separata. 
Na versão italiana de seu DIREITO COMO EXPERIÊNCIA, publicada pela Editora Giuffrè, Milão, em 1973, sob o título IL DIRITTO COME ESPERIENZA, obra em que Reale expõe os desenvolvimentos de sua concepção tridimensional com base em elementos os mais vivos e atuais da cultura contemporânea, sociológica e antropológica além dos propriamente filosóficos, o Jusfilósofo italiano, Domenico Coccopalmerio antepõe um ensaio com 76 páginas sobre as obras e concepção de Reale, advertindo logo que esta versão italiana, em razão da precisão e dos aprofundamentos nela dados por Reale, constitui uma segunda edição atualizada e completada da edição brasileira. De páginas 76 a 85 acresce uma "Bibliografia sistematica degli scritti di e su Miguel Reale".

Com esta citação, o que mais queremos ressaltar do ensaio de Coccopalmerio é que, como Recaséns Siches, aponta a concepção peculiar do Mestre brasileiro, e a destaca como "A FORMULA REALE": Esperienza giuridica e "tridimensionalismo specifico" (la "formula Reale').

A referência que fizemos aos citados Mestres da USP, em primeiro lugar o foi em razão do relacionamento que sempre tivemos com eles e em segundo por podermos deles falar na qualidade de aluno e como aluno fazer indagações sobre suas condutas.

Como explicar a extensão de ensino alcançada por tais Mestres e como classificar suas atitudes?

Do ponto de vista ainda não filosófico, mas jurídico, é fácil uma primeira explicação, tendo-se em vista que "jus et obligatio sunt correlata": partilham o tempo de sua intencionalidade de tal modo que, reservando seu tempo intencional enquanto "direito de estar só" para dedicá-lo aos livros que sabem escolher e que sabem escrever, dedicam a outra parte do seu tempo intencional à obrigação ou dever que se impuseram ao ótimo da comunicação, do ensino, do diálogo e da publicação de suas obras. São Professores-Líderes.

Mas como qualificar a atitude assumida por Mestres como esses que, ultrapassando as obrigações jurídico-contratuais, assumidas "interna corporis" com os estabelecimentos de ensino, chegam a criar Escolas, concepções próprias e estender seu ensino no espaço e no tempo?

Esta não é obrigação decorrente da norma legal, nem por ela qualificada, mas antes da norma subjetiva do modo de ser, do ser na plenitude consciente do sentido de sua vida terrena, na busca dos valores, tanto assim que, superadas as exigências legais dos concursos, tais Mestres passam a "professar" o ensino.

No trabalho sobre a interpretação do Fausto de Goethe, que o Jusfilósofo tridimensionalista Wilhelm Sauer acrescenta à sua magnífica obra JURISTHISCHE METHODENLEHERE, cujo trecho traduzimos e anexamos ao final desta coletânea, é que encontramos as 
mais belas, edificantes e convincentes explicações e respostas, do ponto de vista filosófico, das condutas de Professores exemplares. Vejamô-las.

Indignado com a ascenção da alma de Fausto, o diabo que só sabe pensar e agir "bidimensionalmente", supunha, que pela sua interpretação literal, fria a estanque do contrato tinha direito adquirido sobre aquela alma; não podia compreender a salvação de Fausto; no entanto este a merecera, por ter pensado e agido "tridimensionalmente" na busca dos valores, alcançando o valor acima da própria vida; Deus que permitira o contrato estava certo e não errara, nem podia ter errado em seu prognóstico valorativo, porque tinha a visão da "quadridimensionalidade": do fato, da norma, do valor humano e do valor divino. Por isso, como mandatários da Divindade, sentenciam os arcanjos, ao ascenderem com o imortal de Fausto:

"Quem sempre se esforçou, procurando progredir, pode ser salvo por nós"

E Sauer explicita:

"Somente um homem bom pode realizar algo positivo na profissão de sua vida, seja como artista, como pesquisador, como funcionário, como juiz, como professor e assim por diante"

Cabe, pois, aos alunos desses Mestres se reunirem cada vez mais em torno das Universidades, das Escolas dos Mestres, dos Institutos, para o estudo e intercolaboração dentro de suas respectivas especializações. O IBDT nada mais é do que um abrigo universitário unindo todos os alunos de hoje e de ontem. É um Instituto de pesquisas e de estudos capaz de reunir e de unir companheiros de iguais inquietações.

Parafraseando Tsehkow, discípulo de Confúcio, no Diálogo 19.23:

"O muro do IBDT chega apenas aos ombros; pode-se olhar por cima e ver o que há dentro. Ao passo que a cerca dos grandes Mestres tem muitas braças de altura. Só entrando pela porta se pode apreciar a riqueza do interior. Mas nem todos dão com a porta!"

A sabedoria dessa civilização milenar, ressalta ainda a necessidade da perseverança no alcance dos objetivos: "o difícil não é criar, mas conservar" e se no caso essa porta é a busca da verdade no campo da Ciência do Direito, é preciso nos conscientizarmos da natureza problemática do Direito, para não desanimarmos com percalços ou aparentes dificuldades.

Em meados do século XIX, Julius Hermann von Kirchmann, quando ainda não se podia falar de uma Ciência do Direito tal como veio sendo elaborada, porque o Direito ainda não ultrapassava da exegese, interpretação, comparação e comentários; na célebre confe- 
rência de 1848, sob o título derrotista: A FALTA DE VALOR DO DIREITO COMO CIENCIA (Die Westlosigkeit der Jurisprudenz als Wissenschaft), arrolando aspectos negativos e críticos, chega ao anátema de que: "três palavras de alteração do legislador e toda uma biblioteca se transforma em papel inútil", como se o Direito fosse apenas legislação.

Entretanto, século após, Eric Wolf retoma o tema para colocá-lo nos devidos termos e traçar a compreensão da natureza dessa ciência humana, precisamente com o título que assim já a explica: O CARÁTER PROBLEMÁTICO E NECESSÁRIO DA CIENCIA DO DIREITO (Fragwirdigkeit und Notwendigkeit der Rechtsweissenschaft).

Desta conferência-ensaio jusfilósofico de Eric Wolf, basta traduzirmos alguns trechos sobre as atribuições do Direito como Ciência:

"As tarefas da Ciência do Direito vão muito além do mero conhecimento das leis e da doutrina da interpretação jurídica. O seu conteúdo não só o direito fixado em forma de lei, mas a totalidade do ordenamento social e econômico, cuja realidade se pode colher extrinsecamente nas instituições jurídicas e nas fontes do direito, como ainda nas relações e nas controvérsias jurídicas. O ordenamento jurídico como objeto de uma pesquisa científica tem ainda um conteúdo interno: este se pode encontrar no sentimento jurídico dos cidadãos, na sua obediência ao direito, no seu reconhecimento voluntário da totalidade do ordenamento e suas partes.

Mesmo este sentimento jurídico interno, que felizmente é eficaz, mesmo independentemente de qualquer coação, é uma realidade social. O sentimento jurídico interno e o ordenamento jurídico externo são, na vida histórica dos diferentes povos, alguma coisa que se apresenta à primeira vista distinto, mas logo em seguida idêntico nos aspectos fundamentais e em muitas particularidades, alguma coisa que continuamente muda e se transforma.

Por isso a Ciência do Direito deve se ocupar tanto do direito historicamente passado quanto do direito vigente e do direito futuro; ela estuda e compara ordenamentos regionais e internacionais.

Além disso a Ciência Jurídica compreende e sistematiza a totalidade da vida jurídica, entendida como ordenamento da organização política, religiosa e social e como expressão da diferenciação sociológica em classes e grupos.

Enfim é necessária ainda uma maneira de proceder cientificamente obrigada, para que o ordenamento jurídico seja eficaz e possa ser defendido contra quem quer que $o$ ofenda". 
Portanto a Ciência do Direito não se limita à lei e também a lei não destrói a biblioteca. Como ressalta Reale, o Direito abrange a concreção tridimensional incindível, de fato-norma-valor. Por isso mesmo o estudo jurídico ou científico do Direito não só não se limita à legislação, mas tem de se estender ao universo do Direito, exige o estudo teórico, aliado com o da técnica e da prática do Direito ${ }^{2}$.

Eis a razão de ser e eis a perseverança da Mesa de Debates dentro do Direito Tributário.

Dia 30 de junho de 1983 já alcançou sua quadringentésima (400?) realização. É uma reunião e união dos que desejam se informar e prestar informações, aprender e ensinar por meio do diálogo: enfim chegar democraticamente a soluções com o concurso de opiniões que, dentro de uma especialização se imponham pelo seu conteúdo de valor e pelo grau de convencimento que possam infundir através da técnica, da experiência e da ciência do Direito Tributário.

Para a continuidade e expansão dos estudos e da prestação de seus serviços o IBDT espera contar, cada vez mais, com o interesse e o apoio de seu Associado.

Esta entidade foi idealizada sobretudo como órgão de congraçamento dos tributaristas e sua união em torno de estudos que os acomunam por iguais inquietações. Se estes estudos são de interesse funcional ou profissional de uma categoria, também o são, de modo geral, da coletividade a que esta categoria tem o dever de servir em razão de sua habilitação. Se esta habilitação formalmente exige o diploma, substancialmente exige o constante estudo e atualização, no tempo e no espaço, à procura das melhores soluções.

Especialmente no campo problemático do Direito, nem sempre é possível ao estudioso, isoladamente, descobrir a verdade ou formar sua conviç̧ão.

O Código de Processo Civil, no capítulo das provas refere que "ninguém se exime do dever. de colaborar com o Poder Judiciário para o descobrimento da verdade" (art. 339). Isto é quanto à "relação fática", mas a dinámica ou processo do conhecimento da relação de direito, especialmente no campo tributário que é sobremaneira múltiplo em categorias de normas e sob constante modificações, vem exigindo, cada vez mais, essas intercomunicações de muitas sentinelas.

Se, de um modo geral, ninguém pode alegar a igrorância da lei e todos devem colaborar para o descobrimento da verdade, "a fortiori" os investidos dessas funções ou profissões. Assim sendo, as intercomunicações entre estes no sentido de maior expansão de informações e conhecimentos não é só um dever, mas uma espécie de "seguro contra riscos no caminho do cipoal ou atual parafernália fisco-tribu-

2. Vide em nosso CURSO DE DIREITO TRIBUTARIO, 5* edição Saraiva, S. Paulo, 1980, a partir da pág. 21: Método de Estudo do Direito Tributário nas Faculdades de Direito. 
tária". Neste sentido é que a reunião em Mesa de intercâmbio de informações e de conhecimentos vai se tornando cada vez mais uma instituição de confraternização de colegas, de garantia contra riscos e sobretudo de solidariedade na partilha de conhecimentos especializados.

Se estes trabalhos estão sendo efetivamente úteis a todos os componentes da Mesa, porque não ampliá-los e levá-los ao conhecimento de todos os Associados, pedir-lhes que também colaborem na divulgação do que julgarem certo e, mais ainda, possibilitar a todos os demais interessados o conhecimento, apreciação ou possível utilização desses estudos?

Foi por isso que, após 12 anos de experiências com essa Mesa de Debates de casos e problemas sempre atuais, atuante e renovados, a Diretoria e o Conselho do IBDT - que desejam o comparecimento do maior número possível de seus Associados - verificando a impossibilidade da presença dos que residem distante, deliberou a publicação desta série DIREITO TRIBUTÃRIO ATUAL, cujos volumes 1 e 2 já foram editados com os casos ou problemas que despertaram maior interesse.

Dado o elevado custo das edições encadernadas, até aqui o IBDT tinha conseguido oferecer essa publicação aos associados, com 50\% de desconto sobre os preços de livraria.

Entretanto, os objetivos da divulgação dos trabalhos apresentados à Mesa de Debates precisam maior expansão.

São trabalhos sobre os principais assuntos que na atualidade estão preocupando os tributaristas; são trabalhos para colaborar na preparação da Reforma Tributária; são casos e problemas que estão em discussão nos tribunais; são, finalmente, questões sobre as quais muitos associados estão pesquisando ou estudando e que além de lhes poderem ser úteis, poderão motivar seus estudos e colaboração aos trabalhos em pauta, inclusive sobre projetos em preparação nos Ministérios ou em discussão parlamentar.

Assim sendo, o IBDT deseja que, automática e gratuitamente, todos os Associados venham a receber esta publicação em seu endereço. Por isso reestudou a possibilidade de preparar em sua Secretaria o serviço destinado à impressão e, a partir deste vol. 3, co-editar esta série de coletâneas, mais economicamente com capa plastificada, para não só poder adquirir o número de exemplares suficientes para essa distribuição, mas também assumir as despesas de embalagem e remessa.

Deste modo, os demais interessados, não associados, poderão adquirir esta publicação pelo preço normal nas livrarias, enquanto o IBDT terá o prazer de oferecê-la a seu Associado. Comparado com - preço de livraria cada Sócio poderá vir a receber mais do que o valor da sua contribuição anual, mas isto o IBDT agora já poderá fazê-lo graças à organização administrativa e financeira que atingiu. 
Com a prestação de mais este serviço o IBDT espera estar correspondendo ao constante apoio e prestigio que lhe vem dando cada Associado.

Não podemos deixar de ressaltar que, além da consideração que o IBDT vem recebendo de cada Associado, os mais eminentes Mestres nacionais e estrangeiros integrantes de seu quadro de sócios honorários também o vêm prestigiando, não só com a remessa de notáveis obras dentro do intercâmbio cultural para enriquecer a Biblioteca especializada da Faculdade, mas ainda contribuindo com seus escritos para as publicações do IBDT.

Reconhecido por unanimidade do Conselho Universitário e pela Reitoria como entidade complementar à Universidade de São Paulo, o IBDT é dirigido por Professores das áreas de Direito Tributário, de Direito Tributário Aplicado, de Legislação Tributária e de Direito Tributário Comparado do Departamento de Direito Econômico e Financeiro da Faculdade de Direito da USP e de renomados especialistas.

Assim integrado na tradição e nas preocupações de ensino da Faculdade de Direito do Largo São Francisco, seu cbjetivo é conseguir, cada vez mais, como entidade complementar, auxiliar o ensino, a pesquisa e a prestação de serviços à comunidade, finalidades estas que são as mais nobres e fundamentais da Universidade.

U CONTRATO ENTRE FAUSTO E O DIABO. OCORREU, OU NÃO, INFRAÇÃO CONTRATUAL? VIDE A DECISÃO DIVINA SOBRE O "MÉRITO" 


\section{- A VIDA E A PROCURA DOS VALORES. \\ - A LETRA DO CONTRATO E A INTERNACIONALI- DADE DAS PARTES.}

\section{Ruy Barbosa Nogueira}

Henry Lichtenberger, Professor da Faculdade de Letras de Paris, na introdução de 98 páginas que antepôs à sua notável tradução francesa do primeiro e do segundo Fausto de Goethe, em 3 volumes, publicando-a cuidadosamente pelo sistema bilíngüe, com os textos do original e da tradução em paralelo, que tanto ajudam o leitor na compreensão de ambos os testos ${ }^{1}$, a inicia com estas palavras:

"Fausto é, sem nenhuma espécie de dúvida, a confissão, a mais genial e a mais profunda que Goethe nos doou, a obra mestra em que resume da maneira a mais expressiva, a sua vida, o seu pensamento, toda a sua personalidade".

Se a leitura e a compreensão dos textos sublimados do Fausto de Goethe são difíceis aos próprios autóctones da língua alemã, não só pelo seu "höchst deutsch", mas pela profundidade da temática só realmente alcançada pelos Goethólogos, entretanto com o auxílio de traduções em tantos idiomas e sobretudo através das suas interpretações literárias, teatrais e musicais, hoje também tão difundidas pelos instrumentos da técnica eletrônica, podemos, até certo ponto, participar desses conhecimentos em torno da problemática humana e do aperfeiçoamento espiritual, cada vez mais necessário ao homem enquanto só e, mais ainda, para alcançar a melhor intencionalidade na relação com seus semelhantes.

Obras como as de Sócrates, Platão, Aristóteles, Kant; Homero, Sófocles, Eurípedes, Dante; Shakespeare, Molière, Goethe, Camões; Bach, Mozart, Beethoven; Newton ou Einstein, são evidentemente difíceis aos próprios iniciados ou hoje especialistas, precisamente porque são obras de gênios que abrem caminhos e muitas vezes somente são compreendidas muito depois.

Neste último sentido e, apenas como exemplos, Bach no "temperamento" do Cravo só foi muito mais tarde entendido e explicado através da matemática pelos físicos, hoje engenheiros de som (cfr. Musiciens Poètes, Adolphe Boschot, Librairie Plon, Paris, 1937: A propos du "Clavicin Temperé" et du "Temperament", pág. 189 e segs.). Mozart até hoje não foi ultrapassado na polifonia. E o universo de Einstein na extensão espacial do homem?

Relembrando os conselhos de Alexis Carrel (L'HOMLME CET INCONNU e RÉFLEXIONS SUR LA CONDUITE DE LA VIE) voltemos ao nosso assunto - a extensão espiritual do homem - ao Fausto de Goethe.

1. Editions Montaigne, Fernand Aubier, Editeur, 13, Quai de Conti, Paris. 
Desejamos apenas nos referir a uma interpretação jusfilosófica da temática sobre a procedência ou improcedência do protesto do diabo contra o que ele não pode entender e acusou como inadimplemento do contrato feito com Fausto na presença de Deus. Para Mefistófeles houve infração contratual; fora ferido seu "direito adquirido"; Deus teria sido conivente porque admitira a liberdade contratual e ele diabo como parte não tinha agora sequer Tribunal a que pedir justiça ou reparação da ofensa de seu direito.

Quid juris?

A magnífica interpretação do Jusfilósofo Wilhelm Sauer, que afinal damos em tradução, socorre-se ainda da encenação teatral, dos recursos da música. Lendo a sua interpretação em paralelo com a audição do primeiro e do segundo Fausto na encenação dirigida e participada por Gründgens, ator que até hoje talvez tenha sido o melhor intérprete da personagem de Mefistófeles no Fausto de Goethe, bem nos convencemos dessa magnífica interpretação e explicitação de Sauer que encontramos às págs. $605 \mathrm{e}$ segs., da sua grande obra sobre a metodologia jurídica (JURISTISCHE METHODENLEHERE publicada em 1940, Ferdinand Enke Verlag, Stuttgart, Neudruck 1970, Scientia Verlag Aalen).

Por falar em tradução, em seu ensaio sobre os diferentes métodos de traduzir (Überdie verschiedene Methoden des Übersetzen), ensina o doce teólogo Schleiermacher que a tradução pode levar a linguagem do autor ao leitor, mas que a melhor tradução é aquela capaz de trazer o leitor à linguagem do autor. O grande filósofo espanhol Ortega y Gasset adverte que a tradução não é a obra, é apenas um caminho em direção à obra original. Ajude-nos, pois, o leitor, com a contribuição de sua inteligência, cultura, imaginação e, sobretudo, emoção do belo, para captarmos não só o conteúdo dos momentos mais expressivos até chegarmos a compreender a técnica e a arte atingidas nos contrastes das concretudes da bi, tri e quadridimensionalidade e vermos afinal que Goethe, pela explicação de Sauer, aponta-nos também as escalas da maldade, da bondade e da divindade.

Eis o trabalho de Sauer, sobre a interpretação do Fausto de Goethe:

"Existem problemas literários, cuja superação tem sido tentada, com sucesso bastante variado, mas que podem receber uma solução surpreendentemente simples e quase natural, quando forem examinados sob aqueles critérios rigorosamente metodológicos em que se baseiam todas as grandes criações espirituais.

Se for permitido examinar e interpretar num âmbito restrito a maior obra do maior poeta alemão em relação à sua problemática tantas vezes tratada, será justamente neste exame que o método das ciências humanas se mostrará tão natural, tão necessário organicamente, que se poderá chegar até à idéia de que ele foi desenvolvido diretamente naquela obra, como se tivesse sido copiado dela, como, 
aliás, a filosofia de vida revelada na poesia do Fausto serviu de exemplo e orientação para muitos filósofos posteriores.

$\mathrm{Na}$ verdade, é somente um paralelo natural entre as criações da Arte Superior, de orientação metafísica, e as ciências humanas; ambas procuram, com seus meios radicalmente diversos, apresentar a vida como valiosa e dirigida à eternidade.

Será que, assim sendo, um método das ciências humanas, elaborado de acordo com os mesmos critérios, não é indicado para esclarecer supostas contradições e trechos obscuros numa obra-de-arte?

A harmonia artística e as leis científicas não se baseiam na mesma unidade metodológica?

Sabidamente os intérpretes viram no contrato entre Fausto e Mefistófeles um tema básico da poesia do Fausto.

A filosofia de vida de Fausto soa paradoxos: a minha vida deverá ser perdida quando, em algum momento, eu chegar a afirmá-la e isto nunca acontecerá: "se eu disser ao momento, permaneça pois! Tu és tão lindo! Daí poderás prender-me com as correntes, porque nesse momento eu quero perecer". E Fausto aposta que nunca na vida ele falaria assim. Esta aposta é ganha por Mefistófeles, porque Fausto chega efetivamente a falar isto. o Céu.

Mesmo assim, Mefistófeles não recebe o prêmio. Fausto vai para

$\mathrm{E}$ o diabo, por isso, sente-se enganado e ludibriado: "quem me propicia meu direito adquirido"?

Será que aqui há uma falha de Justiça na dramaturgia?

Nisto reside um problema muito discutido.

A solução deve ser procurada na seguinte direção: Mefistófeles só consegue pensar "bidimensionalmente"; Fausto pensa "tridimensionalmente"; e Deus tem a visão de tudo "quadridimensionalmente".

Mefistófeles vê e vive somente a vida e, em segundo lugar, ele a pensa agudamente em formas e conceitos externos, de maneira racional exagerada, à moda do diabo. Ele vê e reconhece somente o cumprimento formal do contrato, enquanto Fausto, de fato, afirma a vida e ao mesmo tempo a perde.

Por isso, resta ao diabo e ao seu reino o mundo terreno, somente o casco externo de Fausto, somente seu cadáver, somente o ser sensorial (somente os corporais que restaram do homem).

No entanto, metafisicamente é afirmado o anseio de Fausto para alcançar valores em que se baseia a vida, o que Mefistófeles não pode compreender porque seu reino é somente deste mundo ou seja, é somente este mundo. 
A solução não pode ser outra. Pois quando Fausto quer prender o momento da vida, isto não mais é vida, porque a vida é aspiração, mas também inquietação, paralisação e morte.

Meta e sentido da vida não podem residir na vida, mas somente além da vida, ultrapassando a vida. Com a afirmação da vida esta deixa de ser uma vida cheia de sentido como anseio permanente de ultrapassar a vida.

Metafisicamente, portanto, a ânsia de Fausto para alcançar os valores se afirma para além da vida; isto se realiza naquela forma poética, incomparavelmente bela, de uma reprise musical com um "crescendo" gigantesco, alcançando a eternidade: "Queria dizer ao momento: permaneça, você é tão belo! O rastro dos meus dias na terra" (isto é, minha busca de valores) não perecerá nos "Aoenen" (isto é, a busca de valores tornar-se-á elemento essencial da eternidade, mostrar-se-á, portanto, "monaden" de valor; os Aoenen" são objetivamente mais ou menos equivalentes aos "Monaden"). Neste "momento" Fausto vive o "momento mais elevado" e morre. E "os anjos sobem ao céu, levando o imortal de Fausto".

A justificação reside no seguinte: "Quem sempre se esforçou, procurando progredir, pode ser salvo por nós". E com isto, como diz o coro final, o "acontecimento imperfeito", isto é, o inacabado de todo fenômeno da vida transforma-se numa realização perene do ser, em valor da eternidade.

A aparente contradição explica-se, pois, metodologicamente, da seguinte forma:

No reino dos fatos da vida, Mefistófeles, ganha a aposta, mas no reino dos valores ganha Fausto. Pois Fausto adquiriu um direito à eternidade; porque ele passou por todos os reinos da vida, por todos os degraus da cultura, por todos os países e tempos, por todas as épocas da história, natureza e estado, arte e religião, ciência e economia, tendo, nisto, resistido, internamente, isto é, pelo fato de continuar sempre sua busca de valores, a três tentações: na tragédia de Gretchen, na tragédia grega e na tragédia do soberano ou do poder.

Vence, portanto, a justiça.

Mas ela vence também perante o diabo, porém, dentro de um ponto de vista superior ao da própria visão de Fausto, ou seja, dentro da quarta dimensão da visão divina.

Tanto assim que o diabo ainda fez uma segunda aposta, perante o Senhor, no "Prólogo, no Céu". E esta aposta ele, diabo, a perdeu.

Deus lhe deu livre ação na terra ("Pois bem, fica-lhe entregue, veja se pode tirar esse espírito de sua fonte original").

Deus o onisciente, naturalmente faz o prognóstico certo; o diabo nunca o conseguiria, porque "um homem bom, na sua ânsia obscura, é bem consciente do caminho certo". E somente um homem bom 
pode realizar algo positivo na profissão de sua vida, seja como artista, como pesquisador, como funcionário, como juiz, como professor e assim por diante.

No entanto, esta busca terrena de valores continua na eternidade: "se eleva a círculos mais altos, continua crescendo imperceptivelmente".

De cada grau de perfeição que se alcança neste tempo, na terra, passar-se-á diante na outra vida: a eternidade não conhece nenhuma paralisação. E como existem os mais variados graus na natureza (no interlúdio, existe o título melancólico: "dia cinzento, campo", até às alturas iluminadas das montanhas e assim por diante) também a eternidade conhece "uma região profunda, uma intermediária" etc. e nela vivem "anjos mais novos, anjos mais perfeitos", "penitentes", "jovens em estado de graça".

Por isso a luta de Fausto pela imortalidade se purifica somente de forma paulatina; e a decisão é tomada no último círculo, sendo que Goethe retoma um motivo de Dante, ao qual pertence a antiga amada de sua juventude, como penitente perdoada: decidido pelo "eternamente feminino", como símbolo do amor divino. Mas também, a verdade e a justiça somente amadurecem em degraus. Na sua perfeição, verdade e justiça somente se encontram em Deus e elas são Deus.

Na sua grande obra se perfaz maravilhosamente a unidade poética: no "Prólogo, no Céu", o Deus onisciente profetizou a verdade e pôs ao homem a justiça como tarefa infinita; e, no fim, vencem a verdade, a justiça no reino da eternidade, conquistado pelo espírito do ser humano, perante Deus e em Deus.

À harmonia poeticamente estruturada se une, pois, a coincidência dos valores metafisicamente vividos.

A grande poesia do mundo não poderia ter encontrado em outra unidade cósmica mais maravilhosa, a sua perfeição. 